\title{
How to Recognize a Literary Fugue When You See One? Literature in the Context of Intermediality
}

\author{
Joanna Barska
}

\begin{abstract}
The history of reflecting on relations between literature and music is not only a history of searching for artistic manifestations of such a relationship, but also, or perhaps primarily, the history of a search for finding a way to adequately comment on them, a search for a methodological formula. Musico-literary studies, situated in a vaguely defined "in-between" space, are, as Harold Bloom would put it, anxiety-stimulating. This fear stems from our overwhelming need to systematize, to hierarchize, and to establish relations. It is difficult to define what kind of work we describe as "musicalized" fiction, i.e. a unique musico-literary hybrid, which we strongly desire to find regions of stability in, to define the subject of our studies, and to find more tools for verification.
\end{abstract}

Index Terms-Literary fugue, comparative literature, interart studies, music and literature.

\section{TwO APPROACHES TO READING}

Stanley Fish begins his well-known article, How to Recognize a Poem When You See One, with an anecdote about a lecture on $17^{\text {th }}$ century English religious poetry. At the beginning of the class he asked his completely oblivious students to analyze and interpret a text: a list of six names of linguists, which he wrote on the blackboard during the previous lecture. The students were unaware of this and interpreted the text in accordance with the subject of the lecture; they understood it as an Old English, hieroglyphic religious poem and kept coming up with new contexts for its interpretation, all of which were associated with the Judeo-Christian tradition. The religious nature of the "poem" thus naturally became the basis for the search of its typical interpretative characteristics. This meant that the interpretation itself was limited to adjusting possible interpretations to the subject of the class. Similar automatic responses are also apparent during deliberations on the musical inspirations of literary works' structures, a subject this paper also covers.

Musico-literary studies have continued to attract increasing interest in recent decades, and they also continue to serve as a basis for discussion about "the method". Although they are a subject of literary studies, they are on the fringe of the discipline. Moreover, their authors, wishing to avoid accusations of having a tendency to metaphorize or to over-interpret, emphasize the need for a negative research perspective. In doing so, they try to achieve a sort of a compromise between two extreme research approaches: ignoring musical affiliations and focusing on purely literary

Manuscript received April 6, 2015; revised September 1, 2016.

Joanna Barska is with University of Warsaw, Poland (e-mail: j.barska@yahoo.fr). analysis, or identifying musical structures, means, and techniques in a given work on the basis of a priori assumptions, which is sometimes suggested by scholars [1]. The former approach, typical of literary analyses conducted by i.e. Anthony Burgess [2] and Jean-Michel Rabaté [3], is usually a natural consequence of the latter. It acts as a "defense" against the blurring of boundaries and excessive multiplication of intermedial parallels, which stem from poor methodology (terminology, research tools), an explicitly defined subject of research, and criteria for identifying a given model [4]. As Werner Wolf writes, there are some skeptical opinions, which question not only the notion of "musical prose", but also the possibility of the quality of prose coming anywhere near close the quality of music. This should come as no surprise, considering that "musicalization" as a term is often abused, and that it became indicative of the critical discourse's "impressionist metaphorization" [5].

Nowadays, we consider musico-literary intermediality to be a natural response to textual hybrids; its history already spans a few decades [6], and it is included in a field called in Western studies either comparative arts, interart(s) studies, and recently most often-musico-literary intermediality [7]. As the status of these studies changed, less attention is paid to presenting careful argumentation. In a discussion on literary studies, this brings us dangerously close to what one theorist called a slavish adoption of someone else's concepts without knowing their meaning, and what another described as a worrying and even irritating "thoughtless treatment of terms:" "What worries me and poses a problem," he wrote about literary studies in general, "is not so much metaphorization as another related though different trend: the thoughtless ambiguity of the terms people use, and as a consequence - the lack of a clear definition" [8]. Obviously, the process of transferring terms from music to literature and vice versa, has to involve some loss of meaning as a result of these notions' functioning in different contexts and sign systems. Such vivid analogies and metaphors as the literary form of rondo, fugue, polyphony, musical narration etc., require a more minute description and definition in order for a given interpretation to fulfill a greater role than simply that of a stylistic embellishment, and they ought to be considered a notion within a specific semantic framework. We must remember that we are no longer discussing issues that belong purely to either literary studies or to musicology. This is especially important when a literary work involves a musical aspect, where certain notions cannot be adopted with their entire musicological scope of meaning, if only due to their inadequacy in the linear medium of literature. At the same time, it is frequently a practice among literary scholars to list means and assign them to specific musical forms, so that 
recurring themes are at the same time interpreted as a counterpoint, a leitmotiv, and a refrain.

\section{What ABOUT THAT Fugue?}

In literary criticism, many works are branded as "literary fugue" when compared with the Sirens episode from James Joyce's Ulysses, since this chapter is recognized as one of the most brilliant interpretations of musical structure in literature. Let us take a look at the problem of musicalization in works of Iwaszkiewicz, frequently discussed by Polish literary scholars Comparing Wieczór u Abdona [An Evening at Abdon's] and the Sirens, one of the critics writes that "both pieces attempt to introduce the fugue form into literature" [9]. His paper is not so much an analysis of Wieczór... in terms of its musical form, as a discussion on the similarities the short story shares with Joyce's work. The author identifies the "leitmotivs" and their variations, the links between musical and erotic themes, the sound instrumentation. He seeks for similarities in both writers' inspiration with the music of Wagner, and admits that Iwaszkiewicz adopts a completely different approach to the compositional features of the fugue than Joyce: "The typological parallel between Sirens and Wieczór u Abdona is one more possible piece of evidence for the metaphorical nature of musical terms used in studies on works of literature" [10]. What is supposed to indicate the attempted "musical" composition of Iwaszkiewicz's story? As the critic writes, "reading the whole (with the coda in episode XXXIV)":

- These two literary fugues are similar not so much thanks to their composition (which is where we would expect a substantial similarity) as to their themes [the symbolism of colors, female exhibitionism, the motif of music and mathematics - J.B.], which most likely had their model and beginning in modernist fascinations with Wagner. The recurring themes (leitmotivs) in both works are also taken from Wagner; they are treated and exploited differently by Joyce and Iwaszkiewicz: the former gives these motifs greater power of suggestion through the ambiguity and complicated arrangement of these perseverations, while the latter is satisfied with merely sketching the lines of the motifs themselves and revealing some interweaving of those lines [11].

Thus, the claim that Iwaszkiewicz's story is a fugue is based on the striking similarity its theme shares with Sirens, although the growing skepticism of Joyce's commentators as to the episode's musical form is also stressed. However, it is not the theme of the piece that should define its form (only think what would happen if that were to be accepted as an indicator!), and so we are left with the argument of leitmotivs. Leitmotivs, however, are more typical of operas or program symphonies. In the context of all the arguments mentioned so far, the idea he accepts a priori appears to be too far-fetched, especially since in this case Iwaszkiewicz mentioned nothing about the form of his story.

Most of the time, however, the writer's own assertions are a basis for interpreting his works in the context of musico-literary intermediality. Let us look at Martwa pasieka [The Dead Apiary], which supposedly assumes the form of a particular piano sonata by Stravinsky. Iwaszkiewicz writes:
Here, the elements that define the composition are not individual descriptions or phrases, but every sentence, even every word has a well-thought-out special position within the piece. Therefore this story, like many others, has a certain musical form. What is important for the reader is to notice this and not the plot as such, which is absurd and makes no great sense [12].

This strategy can be treacherous, as is obvious in an insightful paper by Maria Woźniakiewicz-Dziadosz [13]. With the above quotation in mind, she provides a detailed analysis of the story's form. To quote only her conclusion:

- Analyses of the literary and musical genre models for Martwa pasieka aim to show that the author's suggestion in his commentary is provocatively misleading, because the story does not realize the sonata form very clearly or unequivocally, since in it one can find - based on the same elements of the text [emphasis added - J.B.] - the structure of a dodecaphonic composition. The musical structures, invoked allusively and incompletely, like the discussed literary genre pattern substantiate the work's perverse motto: 'If I feign wisdom, that is in fact philosophy.' Therefore the musical and literary allusions signify 'pretending' that the work invokes well-known and meaningful structures, and form an important element of a writing tactic that involves playing games with the readers' artistic experiences as they seek order and meaning even in defiance of the writer's own commentary. And such a meaning is suggested to the reader by references to traditionally meaningful structures, such as the form of the sonata, while at the same time being questioned by the suggestion that it is possible to arrange the elements of the piece differently .... Hence, the 'musical quality' of Martwa pasieka is just as ambiguous as its 'literary quality.' The work becomes such a greatly open form that its elements can be structured according to several different organizing principles... [14].

Stanisław Barańczak proves that commentators possess a special power. In his Nieufni i zadufani [The Mistrustful and the Self-righteous] he divided Karpowicz's oeuvre into three stages "which - as a metaphor - could be described with musical terms: the monody stage, the canon stage and the fugue stage" [15]. Barańczak explicitly mentions the metaphor. When another critic refers to these words, he goes a little further:

- Stage one - of explicitness - corresponds, for example, to the volume $\dot{Z} y$ we wymiary [Living Dimensions] (1947); Kamienna muzyka [Stone Music] (1958) belongs to the canon stage, it is ruled by the order of allegorical statements, ambiguities. Fragments of $W$ imie znaczenia [In the Name of Meaning] (1962) and Trudny las [Difficult Forest] (1964) - this is the polyphony of the fugue. Published in 1972, Odwrócone światto [Inverted Light] proves Barańczak's diagnosis: this is definitely a polyphony of meanings. It is a compositionally developed fugue [emphasis added J.B.], but free of any Baroque ideas of a connection between the world and harmony in music [16].

This is just one of numerous examples in which a metaphor invoked is no longer a metaphor; "deciphering" turns into 
ciphering, and the whole thing begins to resemble a game of Chinese whispers.

What should one do with expressions which, mindlessly repeated, ultimately become "labels?" Speaking about his poem Howl, A. Ginsberg used the term "jazz mass" and "Bach fugue," which J. Raskin - the author of American Scream - enthusiastically took up to indicate the poet's musical preferences:

- With Bach and Fitzgerald in the background while he was rewriting Howl, it's no wonder that he called the poem a "jazz mass" and a "Bach fugue." The poem took on the complexity and the spontaneity of Bach and the exhilaration and the soulfulness of jazz [19].

The phrase, all the more attractive in that it comes from the author himself, is repeated by critics, turning Ginsberg into someone who combined Bach's genius with the freedom of jazz; the writer of a mass, a fugue. What are their arguments? An epilogue that is allegedly a psalm? A blend of lyrical pathos and vulgarisms? The impression of polyphony, and thereby, monumentality?

\section{LITERATURE AND INTERMEDIAL CONTEXTS}

It is up to the scholars to decide where to draw the boundary between the defining elements of adaptations of different musical genres. When reading a paper entitled "The Bible as Fugue: Theme and Variations" [20], regardless of whether presenting the problem in such a way is justified or not, one is tempted to ask: what is it then? A fugue or variations? The two forms are hard to distinguish from one another; if a work has the identifying features of both or some features that can be interpreted in many ways, what is the point of attempting to "fit" it into a specific musical form? There is quite a number of papers stating that Huxley's Point Counter Point is a fugue, but proving this requires more than just a researcher's intuition, the hint provided in the title, which is, by the way, quite ambiguous, or the knowledge about the musical interests of the author. It is the same case with Hesse's Steppenwolf, described as being a fugue and a sonata form at the same time due to its three-movement structure [21], as well as the popular The Counterfeiters by Gide, and Exercises in Style by Queneau.

Variations, the rondo, or the sonata-allegro appear to be forms easier to "impose." The last of these three is attractive to a literary scholar primarily due to its three-movement structure: the exposition of two, usually contrasting themes, followed by their processed versions, and finally the reprise a synthesis that "reconciles" the antagonistic voices. "Fitting" a literary work to the broad $\mathrm{ABA}_{1}$ form appears to be much easier than finding a literary equivalent of the counterpoint. This is the case with The Ghost Sonata by Strindberg, which invokes Beethoven's Sonata in D Minor, Op. 31, No. 2. Some literary commentators assume that each of the three scenes is a dramatic transposition of each of the sonata's movements, although Strindberg never mentioned any correlation between his play and Beethoven's composition [22]. Although it is very tempting to juxtapose the movements of the Sonata in D Minor with the scenes of the play, the analogy hypothesis is impossible to uphold [23].
Apart from imprecise wording and attempting to identify musical constructions without analyzing a work or without sufficiently strong arguments, other dangerous consequences for musico-literary studies can stem from ignoring one of the most important conditions for the development of this field of research: research competence. Insufficient familiarity with either of the disciplines can lead to interpretational abuse. As Umberto Eco wrote, "...wanting connections, we found connections - always, everywhere, and between everything. The world exploded in a whirling network of kinships, where everything pointed to everything else, everything explained everything else" [22]. Eco's argumentation is supported by Stanisław Balbus: "To study the relations between literature and music, you have to be a literary scholar as well as a musicologist (at least a little); to study the relations between poetry and painting, you need to be a poetologist as well as an art historian (at least a little). Or the other way round" [23]. To some extent, the problem of research competence is also linked to the expectations of the readers. If we suggest such measures as adding an appendix containing a glossary of musical terms, simplifying the language of the discourse, or removing musical fragments from a text as being "inappropriate for most 'non-professional' readers," it means we are considering musico-literary intermediality in terms of popular academic literature.

What about the competence and education of the authors whose works we analyze? In the case of "musical" literature, an education in musicology cannot be considered an essential factor, given that writers such as Thomas de Quincey, James Joyce, and Virginia Woolf were interest in music only as amateurs. What is necessary, however, is for them to have known enough about the history and theory of music to avoid mixing up the order or using wrong terminology. However, it is quite a different matter if we consider a works where an individual piece combines at least two media, as is in the case of opera, Lieder, ballet etc. This requires a strictly professional approach. The problem of a certain "literature-centrism" should not come as a surprise, considering musico-literary studies originated from comparative literary studies. Personally speaking, neither is the approach wrong, if we consider the case of literary works with musical aspects, in which the musical medium manifests itself only indirectly, existing in and through the main medium: literature [24].

It is not my ambition to prove whether or not Madame Zilensky or Wieczór u Abdona are literary fugues or display any of their identifying features. Instead, I want to draw attention to the deficient argumentation of literary commentators and to the fact, that generalizations are being made, which are so broad that interpreting other works in the same way would greatly expand the group of potential literary "fugues." Intermedial studies are a field in which scholars teeter dangerously on the brink of subjectivity: we often encounter claims that only express their author's feelings and intuitions, which are impossible to refute or to prove. We can identify the terminology anchored within a given field. Terminology that is unambiguous and raises no doubts as to the meaning, regardless of the interpretational strategy adopted: for a literary scholar these will be terms like "lyrical 
novel" or "metonymy", for a musicologist "rondo" or "stretto". We can also identify one-off quasi-names often inspired by another field of research and dependent on particular researcher's intention. If we add "film" to "etude", or specify that the "nocturne" we speak of is a painting, these will be specific examples. It is sufficient to provide the context and define the medium we are talking about. If we distinguish between "names" and "quasi-names", where names are understood as only those units whose denotation is the same in all considered contexts, we should not doubt that fugue, or rather "fugue," used in the context of the medium of literature, cannot be treated as a name. Therefore, a term developed in a given methodological context is liberated from said context and becomes included in the general academic language.

It is not an issue when H. D. F. Kitto writes in Greek Tragedy that the plot of one of Aeschylus' plays contains no sudden turns, complications, or shake-ups, although it does provide a magnificent crescendo as Eteocles unwittingly continues to dance his minuet with death. The crescendo metaphor is only an ornament cleverly woven into the text, and although it adds nothing to the argumentation, and serves only an aesthetic function, it would be absurd to accuse the scholar of any anachronism or abuse. On the other hand, an excess of such terms used metaphorically in a text studying the links between music and literature would introduce unnecessary chaos which would disorient and irritate the reader; in this context they should be used according to their accepted meaning. When employing notions describing a specific musical problem, we also must accept the semantic "baggage" they carry with them. In order not to turn them into mere free metaphors, one would need to define or describe them in greater detail. For example, does "polyphonic" always have a Bakhtinesque context in literary studies? Is the term "leitmotiv" unambiguous enough not to require further explanation?

Terms from different media are making their way into the vocabulary of interdisciplinary studies. Some are used in their original sense, of course very generally, while others, having assimilated meanings, defined intuitively and ambiguously and often through remote associations. Although employing them carries a certain risk, it can at the same time be cognitively fruitful and open a broader interpretational perspective. However, only when we are aware of the distinction that we can speak of our discipline's methodological awareness: of the boundaries running through it at a certain moment in history; a boundary between knowledge already gained, stored, and secured, and the possibilities for further development of knowledge, hidden in the applied notional apparatus.

\section{ACKNOWLEDGEMENT}

This research project has been funded by the National Science Centre in Poland, according to the decision no. DEC-2013/11/N/HS2/03302.

\section{REFERENCES}

[1] W. Wolf, The Musicalization of Fiction. A Study in the Theory and History of Intermediality, Amsterdam-Atlanta: Rodopi, 1999, p. 4.
[2] A. Burgess, Napoleon Symphony, New York/London: Norton, 1974, p. 349.

[3] J.-M. Rabaté, "The silence of the sirens," in James Joyce: The Centennial Symposium, M. Beja, P. Herring, M. Harmon, and D. Norris, Eds. Urbana: University of Illinois Press, 1986, pp. 82-88.

[4] W. Wolf, The Musicalization of Fiction. A Study in the Theory and History of Intermediality, Amsterdam-Atlanta: Rodopi, 1999, p. 4.

[5] S. P. Scher, "Notes toward a theory of verbal music," Comparative Literature, vol. 22, no. 2, pp. 147-156, 1970.

[6] C. S. Brown, Music and Literature. A Comparison of the Arts, Athens, Ga.: The University of Georgia Press, 1948, pp. 97-107.

[7] L. Kramer, "Dangerous liaisons: The literary text in musical criticism," Nineteenth-Century Music, vol. 13, no. 2, 1989.

[8] T. Walas, H. Markiewicz, M. P. Markowski, R. Nycz, and T. Kunz, "About professionalism, ethics and terminology in literary," Wieloglos, no. $1,2006$.

[9] J. Paszek, "Iwaszkiewicz and Joyce, about the two literary fugues," Twórczość, no. 2, p. 82, 1983.

[10] J. Paszek, "Iwaszkiewicz and Joyce, about the two literary fugues," Twórczość, no. 2, p. 89, 1983.

[11] J. Paszek, "Iwaszkiewicz and Joyce, about the two literary fugues," Twórczość, no. 2, p. 90, 1983.

[12] J. Iwaszkiewicz, "A dead apiary," Musical Short Stories, Warszawa: Czytelnik, p. 289, 1971.

[13] M. Woźniakiewicz-Dziadosz, "Musical categories in the structure of a narrative work, The Beethoven's Timpani by Choromański and A Dead Apiary by Iwaszkiewicza," in Music in Literature: The Anthology of Polish Studies After World War II, A. Hejmej, Ed. Kraków: Universitas, 2002, pp. 301-329.

[14] M. Woźniakiewicz-Dziadosz, "Musical categories in the structure of a narrative work, the Beethoven's Timpani by Choromański and A Dead Apiary by Iwaszkiewicza," in Music in Literature: The Anthology of Polish Studies After World War II, A. Hejmej, Ed. Kraków: Universitas, 2002, pp. 327-328.

[15] S. Barańczak, The Mistrustful and the Self-Righteous, Romanticism and Classicism in Young Poetry of the 1960s, Wrocław: Zakład Narodowy im. Ossolińskich, p. 49, 1971.

[16] I. Szpara, "Argument and function in poetry of Tymoteusz Karpowicz," in Proc. the 5th Academic Session in the Series World is One but Not Homogeneous, Bydgoszcz, Oct. 22-23, 2001.

[17] J. Raskin, American Scream, Allen Ginsberg's Howl and the Making of the Beat Generation, Berkeley: University of California Press, 1986, p. 141.

[18] L. Dudek, "The bible as fugue: Theme and variations," University of Toronto Quarterly, vol. 52, no. 2, pp. 128-135, 1982.

[19] K. Fickert, "Review: Hermann hesse's Steppenwolf and its critics by David G. Richards," The German Quarterly, vol. 70, no. 4, p. 431.

[20] M. Gmys, "About a very specific case of an Ekphrasis: The ghost sonata by August Strindberg and Sonate in D minor op. 31 no. 2 by Ludwig van Beethoven," in Intersemiotic Studies: Literature and Other Arts, S. Balbus et al., Ed. Kraków" Universitas, 2004, p. 99.

[21] M. Gmys, "About a very specific case of an Ekphrasis: The ghost sonata by august strindberg and sonate in D minor op. 31 no. 2 by Ludwig van Beethoven," in Intersemiotic Studies: Literature and Other Arts, S. Balbus et al., Eds. Kraków Universitas, 2004, p. 100.

[22] U. Eco, Foucault's Pendulum, Warszawa: PIW, 1993, p. 465.

[23] S. Balbus et al., Intersemiotic Studies: Literature and Other Arts, 2004, p. 15.

[24] L. Kramer, "Dangerous liaisons: The literary text in musical criticism," Nineteenth-Century Music, vol. 13, no. 2, pp. 159-167, 1989.

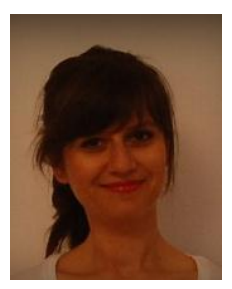

Joanna Barska was born in Gdynia, Poland in 1986, graduated from the Faculty of Comparative Literature, Jagiellonian University in Cracow, and the "Artes Liberales" Academy (the Inter-University Program of Interdisciplinary Studies), she received the master degree in comparative literature, 2010. She is $\mathrm{PhD}$ candidate at the University of Warsaw, Poland (Faculty of Comparative Literature) and the "Artes Liberales" Academy (Inter-University Program of Interdisciplinary PhD Studies). Awarded from, among others, the Polish Minister of Education for the outstanding research; a principal investigator in the individual grant project from the National Science Centre ("Preludium") in Poland. Ms. Barska is a member of The International Association for Word and Music Studies (WMA) in Austria. Her academic interests include: contemporary literature and art, the aesthetics of music, and musico-literary intermediality. 